\title{
Transparência em Defesa: um panorama das medidas de construção de confiança na Unasul (2009-2016)
}

\section{Transparency in Defense: an overview of Unasul confidence and security building measures (2009-2016)}

GRACIELA DE CONTI PAGLIARI JULIANA VIGGIANO

\section{INTRODUÇÃO}

O mundo pós-Guerra Fria assistiu à proliferação de acordos destinados a fomentar a transparência na área de defesa em diversas regiões. As medidas de construção e fortalecimento da confiança (MCCs) são iniciativas que buscam aumentar a transparência de informações acerca de dados concretos, intenções políticas e planejamento estratégico entre os países na área de segurança internacional e defesa, com o intuito de evitar a eclosão de conflitos armados e, em casos específicos, criar as condições para acordos mais ambiciosos voltados para o desarmamento.

A despeito dos percalços enfrentados pela instituição, a Unasul, e especificamente o Conselho de Defesa Sul-Americano (CDS), representaram um momento de inflexão na trajetória de construção de mecanismos regionais destinados a fortalecer a confiança, aumentar a transparência no setor de defesa e buscar convergências nas políticas e agendas de defesa da região. Fortemente alicerçado no objetivo de fomentar a cooperação em defesa, o CDS buscou instituir diretrizes de caráter multilateral que guiassem iniciativas de transparência, especialmente por meio da elaboração de critérios de padronização de procedimentos.

Graciela De Conti Pagliari - Professora de Relações Internacionais da Universidade Federal de Santa Catarina. Cocoordenadora GESED/UFSC. Bolsista CNPq.

Juliana Viggiano - Professora de Relações Internacionais da Universidade Federal de Santa Catarina. Cocoordenadora GESED/UFSC. 
Este artigo propõe-se a apresentar um panorama do desenvolvimento das MCCs no contexto da Unasul entre os anos de 2009 e 2016. Grande parte dos esforços do CDS foram direcionados para a construção de MCCs, considerado pelo Conselho como um instrumento fundamental para alcançar os seus propósitos basilares de garantir a cooperação e a concertação entre os países da América do Sul para criar políticas comuns de defesa para a região.

$\mathrm{O}$ artigo argumenta que o CDS apostou na estratégia de produção de metodologias envolvendo MCCs para criar convergências sobre abordagem e coleta e disseminação de informações acerca de temas considerados prioritários, como forma de fortalecer a confiança regional e a construção de uma identidade coletiva, aprofundando a institucionalização normativa de tais práticas.

Este modelo de aproximação multilateral estruturado em práticas de transparência em defesa não se configura uma novidade. Medidas voltadas para a construção ou fortalecimento da confiança entre Estados consistem efetivamente no principal mecanismo em que se apoiam os países para o incentivo à transparência no setor de defesa em diversas regiões do mundo. $\mathrm{O}$ conjunto de medidas elaborados pela Unasul coexiste com as medidas discutidas e institucionalizadas em diferentes ocasiões também no âmbito da Organização dos Estados Americanos (OEA), com muitos pontos de sobreposição.

O contexto de segurança e defesa regionais da América do Sul, no entanto, apresenta uma característica sui generis. As relações estatais são permeadas por considerável grau de desconfiança ${ }^{1}$ e baixo nível de transparência e, ao mesmo tempo, a praticamente inexistência de guerras interestatais. Os Estados não abdicaram de demonstrações de força e mantêm um conjunto de disputas entre si sem que essas se manifestem na forma de conflito armado $^{2}$ (Mares 2012). Essa condição, ${ }^{3}$ segundo Mares (2012), resulta da pouca eficiência de mecanismos regionais em solucionar disputas. Nesse sentido, o CDS aparece como uma novidade, por consistir em um órgão de concertação exclusivo sul-americano. Em tese, diretrizes normativas construídas a partir de demandas particulares potencializam a implementação mais efetiva de MCCs, por salientarem percepções regionais acerca do que se entende como relevante para a transparência em defesa e a construção da confiança. Ganhos, ainda que de alcance limitado, podem ser encontrados nesses anos de atuação do Conselho, em especial com relação à construção de metodologias e à elaboração de definições comuns que facilitam a troca de informações e ações conjuntas, de forma mais acabada, sobre os gastos em defesa.

A avaliação dos documentos da instituição aponta para uma aceitação cautelosa das medidas sugeridas pelo CDS. No plano normativo, o processo 
de adoção das metodologias propostas fica debilitado pela ausência de mecanismos padronizados para verificação das informações enviadas. A pouca propensão dos países em divulgar seus dados individualizados também demonstra que o fortalecimento da confiança ainda precisa de consolidação.

Esse artigo centra sua discussão nas quatro metodologias propostas pelo CDS para padronizar a seleção e o envio das informações a serem compartilhadas, salientando seus distintos estágios de desenvolvimento e relevância na agenda da instituição. Além dessa breve introdução, o artigo conta com mais três seções. A primeira apresenta a transparência na área de defesa e as medidas de construção da confiança a partir de discussões conceituais e normativas que contextualizam o debate. A segunda parte discute as MCCs elaboradas no âmbito do CDS/Unasul a partir de documentos produzidos pela instituição. Finalmente, a terceira seção conclui o trabalho com observações de caráter tentativo sobre o que sugerem os dados acerca do estágio de desenvolvimento das práticas multilaterais de construção da confiança em defesa na região.

\section{PERSPECTIVA HISTÓRICA E DEBATES ACERCA DA TRANSPARÊNCIA EM DEFESA}

Há duas linhas analíticas bastante claras na literatura sobre a transparência em defesa na região. Uma, que concentra textos e análises na década de 1990, enfatiza tanto a discussão conceitual quanto a apresentação das medidas adotadas na região a fim de reduzir as hostilidades ainda remanescentes das disputas da guerra fria (Varas and Caro 1994 (Orgs.); Caro 1995; Rojas Aravena 1996). A outra salienta tanto o acumulado das MCCs como o papel dos mecanismos de cooperação criados no período que inclui o século atual (Rojas Aravena 2000; 2002; Bromley and Perdomo 2005; Flemes and Radseck 2009; Donadio 2010).

Apesar de um tema amplamente aceito por políticos e acadêmicos como instrumento para aumentar a segurança e confiança entre os países, a transparência no setor de defesa consiste em algo difícil de se alcançar na prática, dada sua complexidade (Lindsay 2011), e não possui critérios de mensuração padronizados que permitam comparar avanços na sua prática (Cheung and Wilson 2014).

A ideia de transparência no contexto institucional usualmente remete a melhorias nos processos de governança, criando maior visibilidade sobre processos decisórios e elementos associados à implementação dessas decisões. Aprimorar os mecanismos de transparência demanda investimento e intervenção direcionados para tal fim. No âmbito da defesa, no plano mais geral, as MCCs são instrumentos que buscam contribuir para a transparên- 
cia, e visam a fortalecer a confiança entre as partes, com o fim de distensionar as relações, ou, por vezes, alcançar acordos mais ambiciosos voltados para o controle de armas, desarmamento, mitigar conflitos com potencial de violência (Desjardins 2004; 2014) e, de caráter mais abstrato e normativo, promover a segurança coletiva (Lindsay 2011). Em uma conferência do Instituto sobre Cooperação e Conflitos Globais da Universidade da Califórnia em 2011, definiu-se transparência em defesa nos seguintes termos:

Transparência em defesa é um processo pelo qual um Estado transmite informações oportunas, relevantes e suficientes, com credibilidade, sobre o poder, as atividades e intenções militares de seu país que permitam outros Estados acessarem a consistência da informação com interesses estratégicos e obrigações institucionais declaradas, reduzindo dessa forma o risco de erros de percepção e cálculo, e, por meio desse processo, construir confiança mútua (Lindsay 2011,3).

Essa definição procura incorporar três temas costumeiramente abordados pela literatura sobre transparência na área de defesa: “1) processo de compartilhamento de informações do Estado; 2) hierarquias e instituições domésticas dos Estados; e 3) os sinais e intenções que as práticas de transparência transmitem” (Cheung and Wilson 2014, 1). Transparência em defesa, nos termos colocados acima, se funda, portanto, em três dimensões igualmente relevantes: normativa, processual e institucional. A dimensão normativa consiste em aceitar a complexidade e o caráter subjetivo do fenômeno, ultrapassando a percepção de que transparência implicaria na simples troca de informações. Trata-se, na realidade, da troca de informações com um propósito maior: aumentar a previsibilidade e estabilidade das relações estatais, que precisam ser entendidas a partir das particularidades do seu contexto, fortalecendo a capacidade de gerenciamento de riscos por parte dos atores (Lindsay 2011; Cheung e Wilson 2014).

A dimensão processual consiste no reconhecimento de que se trata de práticas de constante interação e reinterpretação das informações compartilhadas pelas partes, que determinam o alcance dessas iniciativas em atender ao objetivo de garantir a estabilidade. Por fim, o aspecto institucional reflete o grau de incorporação dessas medidas nas instâncias domésticas, tanto no que diz respeito à criação de mecanismos que afiram credibilidade às informações prestadas quanto demonstrem tendências e direcionamentos associados à manutenção e garantia da paz regional e internacional (ibdem).

$\mathrm{Na}$ prática, a transparência em defesa e segurança internacional traduz-se em diversos acordos dedicados às MCCs. Essas medidas surgiram de forma mais estruturada na década de 1970, com a Conferência sobre a Segurança e a Cooperação na Europa, que deu origem à Organização para 
a Segurança e Cooperação na Europa, a qual se encarregou de revisar e complementar ao longo dos anos as provisões inicialmente acordadas na Ata Final de Helsinki de 1975 (Helsinki Final Act). Revisões foram realizadas pelo Documento da Conferência de Estocolmo em 1986, o Documento de Helsinki em 1992, e os Documentos de Viena, que consistem nas atualizações mais recentes das medidas de transparência, publicados em 1990, 1992, 1994, 1999 e 2011 , sendo esta última a mais recente. ${ }^{4}$

O Documento de 2011 estabelece claramente em seus preâmbulos o propósito de fomentar relações pacíficas e estáveis entre os Estados envolvidos. De acordo com o documento, essa iniciativa consiste em "uma parte substantiva e integral do processo multilateral iniciado pela Conferência sobre Segurança e Cooperação na Europa" e tem como fim estabelecer "em estágios, ações novas, efetivas e concretas desenhadas para se progredir no fortalecimento da confiança e da segurança e em alcançar o desarmamento, de forma a dar efetividade e expressão à obrigação dos Estados participantes a abster-se da ameaça ou uso da força nas suas relações mútuas, assim como nas relações internacionais em geral" (OSCE 2011, 1 (3)). Para esse fim, o documento elabora uma série de mecanismos que devem ser adotados pelos países da organização, fundamentalmente voltados para troca de informação e esclarecimentos acerca de direcionamentos políticos e estratégicos da área de defesa de cada um dos países.

O Documento de Viena estabelece também um conjunto de práticas que englobam informações sobre atividades militares, estrutura das Forças Armadas, delineamentos político-estratégicos, expectativa de verificação das informações oferecidas e o envio de relatórios anuais identificando as MCCs implementadas e previstas para implementação. Além disso, incentiva os Estados-membros a estabelecerem acordos bilaterais, multilaterais ou regionais complementares que aumentem a transparência e a confiança (OSCE 2011, 44). No que diz respeito às atividades militares, a última versão do Documento estabelece com especificidade quantidades e previsibilidade de certas atividades. Por exemplo, no capítulo 5 intitulado "Prior Notification of Certain Military Activities (CMA)" estabelece que os países devem notificar os demais membros sobre atividades de forças terrestres que envolvam ao menos 9.000 tropas, 250 tanques, $500 \mathrm{ACVs}^{5}$ ou 250 peças de artilharia (OSCE 2011, 20). Estabelecem também requisitos e condições a que devem se submeter os Estados membros para inspeções e avaliações. Quanto à dimensão político-estratégica, o Documento prevê o compartilhamento anual de informações sobre as "intenções dos Estados no médio a longo prazo no que diz respeito ao tamanho, estrutura, treinamento e equipamento das suas Forças Armadas, assim como da política de defesa, doutrinas e orçamentos relacionados" e solicita "o aprimoramento 
de mecanismos de consulta e cooperação existentes no que concerne atividades militares incomuns", esse último com o propósito de reduzir os riscos de conflitos violentos (OSCE 2011, 45).

De fato, uma série de iniciativas de natureza militar e política historicamente adotadas pelos Estados foram renomeadas como MCCs. Tal discussão se internacionalizou e se legitimou como um instrumento promissor para mitigar conflitos no final dos anos 1970. O estudo encomendado pela ONU em 1979 a peritos em MCCs conclui, em seu documento final de 1981, que, apesar "das causas subjacentes aos conflitos em muitas partes do mundo [terem] origens distintas, um fator comum de insegurança era a falta de informação sobre as atividades militares de outros Estados e outras questões relacionadas à segurança mútua” (Desjardins 2014, pos. 215).

No pós-guerra fria, a versão predominante sobre a importância das MCCs ecoa as críticas dos países em desenvolvimento à época da discussão no contexto da ONU, denunciando a baixa correspondência das percepções de ameaça dos países europeus, mais voltadas para ataques surpresa e exclusivamente associada a conflitos militares, com os fenômenos não-tradicionais que ocupavam a agenda de defesa e segurança dos países em desenvolvimento. De fato, na atualidade, os objetivos mais limitados das MCCs vislumbrados pelos países europeus em sua primeira formulação, isto é, de conter ameaças de segurança bastante específicas e de natureza militar, procuram estimular a redefinição de percepções e a aproximação entre os Estados (ibid). Nesse sentido, os documentos produzidos no âmbito da OSCE serviram como referência para a adoção de MCCs em diversas outras regiões do mundo, feitas adequações de acordo com as demandas particulares, embora mantendo uma parcela considerável de temas tradicionais da segurança militar, aos quais os Documentos de Viena se mantiveram fiéis.

As MCCs refletem preocupações de defesa e segurança específicas, oriundas dos contextos geopolíticos para as quais tais medidas são formuladas. A construção da confiança, em suma, não implica necessariamente em compartilhar todo o tipo de informação disponível acerca dos assuntos militares (em especial, acerca das capacidades), mas deve atender a demandas específicas dos atores envolvidos, e que represente o que consideram necessário que seja informado ou compartilhado para o fomento da confiança. No entanto, de maneira geral, os termos dos acordos relacionados a MCCs são consideravelmente amplos, e, portanto, com considerável latitude interpretativa que, por um lado, tem o aspecto positivo de facilitar o diálogo; por outro, dificulta a construção de percepções e conceitos mais robustos que sustentem avanços práticos mais significativos na implementação dessas medidas (Desjardins 2014). 
Nas Américas, a OEA ocupou-se de criar o primeiro arcabouço normativo específico para a região, que engloba, além da América do Sul, as Américas Central e Caribe e do Norte. As discussões ocorridas no âmbito da OEA sobre definição de ameaça, contudo, deixaram transparecer a falta de consenso dos países em face das distintas prioridades nas áreas de segurança e defesa, o que dificulta qualquer elaboração de caráter mais específico do que se espera dos Estados em termos de práticas de transparência, assumindo haver efetivo interesse por parte dos Estados em estabelecê-las. ${ }^{6}$ Por consequência, a agenda regional propõe medidas de confiança ${ }^{7}$ amplas, difíceis de serem cumpridas em sua integridade pelos países, sem identidade sobre qual tipo de informação a ser compartilhada torna-se prioritária. ${ }^{8}$

$\mathrm{O}$ documento mais recente de consolidação de tais medidas, publicado pela organização em 2018, divide as MCCs entre iniciativas "tradicionais" e "não-tradicionais", esta última referindo-se exclusivamente a iniciativas que buscam minimizar ameaças de natureza cibernética à segurança e defesa. Em linhas gerais, o conjunto de documentos da OEA incorpora os principais pontos tratados pelo Documento de Viena. Adicionalmente, um conjunto de temas ganham espaço na agenda da transparência na área de defesa hemisférica, refletindo preocupações de segurança e defesa características da região. Dentre outras, a criação de uma metodologia comum para mensuração de gastos na área de defesa entre Estados vizinhos; medidas adicionais para áreas de fronteira e atenção aos desastres naturais. (OEA 2018).

No documento "Conclusões da Presidência da Sétima Reunião do Fórum sobre Medidas de Fortalecimento da Confiança e da Segurança" de 2017, no entanto, afirma-se que, apesar das MCCs estabelecidas pela OEA estarem sendo adotadas, os Estados membros não têm atendido a regularidade demandada pelas Resoluções da organização no fornecimento das informações. Um relatório do SIPRI produzido em 2012 sobre transferência em gastos militares e aquisições de armas na América Latina e Caribe afirma, no entanto, que apesar das deficiências, há aumento "real e tangível" no grau de transparência nesses quesitos na região (Bromley and Solmirano 2012, 34).

Especificamente na América do Sul, o interesse em construir mecanismos de caráter multilateral para o incentivo à cooperação e atividades hoje associadas ao arcabouço de MCCs na área da segurança internacional e da defesa antecede em muitos anos a construção da Unasul. O caminho percorrido pela política de cooperação na região em relação aos gastos militares teve início quando Argentina, Brasil e Chile se reaproximaram e implementaram políticas em relação à construção de uma zona de paz, livre de armas de destruição em massa e de armamentos nucleares. Ugarte 
(2016) cita que, em relação à defesa militar, o marco inicial foi abril de 1987 com o Primeiro Simpósio de Estudos Estratégicos entre os EstadosMaiores Conjuntos de Argentina e Brasil, que posteriormente incorporaram Uruguai e Paraguai, ao mesmo tempo em que incrementavam os exercícios combinados entre eles. Ademais, conformaram, no final da década de 1990, o Mecanismo Permanente de Consulta e Coordenação em relação a questões de interesse dos mesmos em defesa e segurança internacional, permitindo outros acordos de cooperação em âmbito de defesa.

O CDS, portanto, consolida uma prática já presente no contex to sul-americano, tanto em práticas multilaterais quanto bilaterais, com distintos objetivos, graus de complexidade e amplitude. Com a preocupação em estimular a convergência da agenda de defesa da região, o CDS desenvolve e incorpora MCCs, estabelecidas como mecanismos que contribuem para promover seus objetivos principais de "consolidar a América do Sul como uma zona de paz, base para a estabilidade democrática e desenvolvimento integral dos povos", e de construir uma identidade sul-americana em defesa, levando em conta as características sub-regionais e nacionais dos países (Estatuto CDS 2008). O Relatório sobre os Termos de Referência para os Conceitos de Segurança e Defesa na América do Sul (2011, n.p) estabelece a alteração no padrão hemisférico de tratamento da segurança para um de cunho regional, no qual os governos reconhecem "a necessidade de avançar para definições comuns de políticas e sistemas de segurança e defesa e ações cooperativas e complementares nestes campos".

A seção a seguir dedica-se a apresentar um panorama das MCCs elaboradas pelo CDS/UNASUL. Quatro são as medidas apresentadas de acordo com o nível de relevância identificado nos documentos: a) metodologia comum para gastos militares; b) metodologia comum para o Inventário Militar; c) coordenação na área de desastres naturais e d) política de gênero nas Forças Armadas.

\section{MEDIDAS DE CONFIANÇA MÚTUA NO CONSELHO DE DEFESA SUL-AMERICANO: QUADRO DE PROPOSTAS}

Em contraposição ao processo que ocorreu na OEA, a Unasul não produziu nenhum documento especificamente direcionado para as MCCs, embora a atenção com o aprofundamento de tais práticas tenha ocupado significativo espaço na agenda do CDS. As MCCs adotadas pelo CDS consistem, na realidade, em um mosaico de iniciativas selecionadas, de acordo com as percepções dos Estados sul-americanos sobre as demandas de defesa da região, a partir de práticas previamente discutidas nos âmbitos da OEA e da Cepal. Em alguma medida, o CDS busca aprofundar 
e dar às medidas produzidas as características e intereses particulares dos Estados da região.

O "Relatório Final: Desenho de uma Metodologia Comum de Medição de Gastos de Defesa” elaborado em 2010/2011 pelo grupo de trabalho designado pelo CDS para avaliar a possibilidade de se estabelecer medidas de mensuração padronizadas para gastos em defesa, reconhece o envolvimento da região com as MCCs, relaciona o histórico da construção dessas medidas no âmbito da OEA e retoma que a transparência dos gastos em defesa é de fundamental importância em termos de MCCs para nossos países. ${ }^{9}$

No tocante à Unasul, o Centro de Estudos Estratégicos de Defesa (CEED) incumbe-se de formular iniciativas consideradas como medidas de construção da confiança a partir dos objetivos definidos pelo CDS. O CEED foi criado com o propósito de "gerar um pensamento estratégico no nível regional, que contribui à coordenação e harmonização das políticas de defesa na América do Sul" e é o responsável por consolidar, avaliar, publicar e armazenar todas as informações enviadas pelos países relacionadas às MCCs (CEED, página da web).

Os resultados apresentados nessa seção foram obtidos a partir da análise dos Planos de Ação e Atas de reuniões do CDS (2009 a 2016), dos Planos de Trabalho do CEED (2012-2016) e de documentos específicos relacionados à temática produzidos pelo CEED sobre o assunto. ${ }^{10} \mathrm{Em}$ essência, para além dos documentos específicos, os Planos de Ação e de Trabalho consistem nas fontes de maior conteúdo sobre o encaminhamento das iniciativas práticas do órgão, embora muitas vezes sem evidências claras sobre a efetiva implementação dessas iniciativas.

Os Planos de Ação, como sugere o nome, são documentos norteadores das iniciativas de curto e médio prazo do CDS. ${ }^{11}$ A criação do CEED, responsável pela formulação dos Planos de Trabalho, ${ }^{12}$ é em si vista como uma medida de construção da confiança, colocado como objetivo no primeiro Plano de Ação do CDS. Este Centro tem como funções realizar análises sistemáticas e periódicas nos temas de defesa e segurança regional e internacional, estabelecer relações institucionais entre os países membros, fomentar a criação de uma rede de intercâmbio entre centros nacionais de estudos estratégicos por intermédio dos Ministérios da Defesa e atuar como um centro de documentação para memória institucional do CDS.

Essas iniciativas encontram-se descritas e previstas nesses documentos de forma dispersa, não organizadas em seções diretamente relacionadas a medidas de fortalecimento da confiança, e sim incorporadas, juntamente com outras iniciativas, aos eixos temáticos (nos Planos de Ação) e às áreas de pesquisa (Planos de Trabalho do CEED). ${ }^{13}$ 
Pertencentes à agenda tradicional de MCCs, a transparência dos gastos em defesa e a criação do inventário militar dos países da América do Sul são temas que se destacam pela recorrência com que aparecem nos documentos analisados, pelo tratamento concedido aos mesmos nos Planos de Trabalho e nos Planos de Ação, e pelo conjunto de documentos adicionais elaborados no âmbito da organização dedicados a essas questões.

A preocupação com o fortalecimento da confiança por meio da intensificação da transparência dos gastos militares consiste em uma das medidas mais amplamente adotadas e discutidas na área da transparência em Defesa. Como brevemente mencionado acima, a preocupação com gastos militares permeia a agenda da área de Defesa na região latino-americana há algum tempo e foi contemplada pelas recomendações estabelecidas na Declaração do primeiro encontro sobre MCCs da região, em Santiago, no Chile, em $1995 .{ }^{14}$ Nesse primeiro momento, a declaração da OEA sugeria aos Estados membros compartilharem informações por meio do envio do Relatório Padronizado Internacional sobre Gastos Militares, um instrumento elaborado pela ONU. Gradualmente, com as demais declarações produzidas pelo órgão, não somente se incentivava a participação no banco de dados da ONU como também o envio de relatórios anuais previstos pela Convenção Interamericana sobre Transparência nas Aquisições de Armas Convencionais, aprovada pela Comissão de Segurança Hemisférica em 2002. No que diz respeito a metodologias comuns, o Consenso de Miami de 2003 recomenda " $[\mathrm{d}]$ esenvolver metodologias padronizadas comuns de medição dos gastos de defesa em Estados vizinhos” (OEA 2003, 6).

A primeira iniciativa para criação de uma metodologia comum na América do Sul partiu da Argentina e do Chile, que solicitaram em 1998 à Cepal a elaboração de um documento que criasse padrões para medir os gastos em defesa. Em 2001, foi entregue a Metodología Estandarizada Común para la Medición de los Gastos de Defensa, cujas formulações consideram as particularidades das estruturas das Forças Armadas e dos governos envolvidos (Cepal 2001). ${ }^{15}$

A proposta da Unasul parte desse processo adotado em âmbito bilateral e, em 2010, por meio do CDS, inicia a coleta de informações em gastos de defesa dos países participantes da organização conforme a metodologia da ONU. Na fase seguinte, desenhou uma metodologia regional para medição e verificação empírica em um grupo de países (Desenho de uma Metodologia Comum de Medição de Gastos de Defesa 2011), definida como uma das prioridades do órgão em seus Planos de Ação.

Os Planos definem seus objetivos considerando o cumprimento das medidas anteriormente propostas. Trata-se de um processo no qual, gradualmente, segundo a percepção da organização, novos objetivos, que po- 
tencialmente demandariam maior compromisso, poderiam ser definidos uma vez os anteriores tivessem sido cumpridos. Os documentos disponibilizados pela Unasul não nos permitem verificar quais critérios são considerados na validação do cumprimento de um determinado objetivo, mas demonstram a proposição crescente de mecanismos mais ativos, que confiram maior dinamismo ao compartilhamento de informações, como, por exemplo, a proposta para se normatizar o uso das informações fornecidas pelos Estados-membros feita pela Instância Executiva do CDS em 2011.

A transparência dos gastos em defesa, segundo a percepção do CDS, se institucionalizaria a partir da criação de uma rede voltada para intercambiar informações sobre políticas de defesa, gastos militares e indicadores econômicos relativos ao tema. Nesse contex to se cria uma metodologia para medição dos gastos em defesa, capaz não só de contribuir para a transparência na área, mas também atender ao interesse da organização de promover mecanismos que facilitem a articulação de posições conjuntas nos foros multilaterais sobre o tema. O produto institucional do CEED nessa área é a apresentação do Registro de Gastos em Defesa, que consolida os gastos regionais a partir de uma "metodologia padronizada para a apresentação da informação correspondente e em um mecanismo anual para a remição, da informação dos países membros ao CEED, instância técnica responsável pelo seu processamento e sua publicação" (Registro Sul-Americano de Gastos Agregados em Defesa 2006-2010 2014, 21). Como na ONU, a Unasul desenhou um formulário específico a partir do qual os países apresentam informações anuais referentes aos seus gastos em defesa.

Um importante elemento associado diretamente à construção dessa metodologia foi a conceituação comum sobre gastos em defesa que a organização conseguiu produzir (Bragatti and Gonçalves 2018, Saint-Pierre and Palacios Júnior 2014). Definiu-se gastos em defesa como "todos os recursos alocados pelo Estado para financiar as atividades que compõem a segurança externa da Nação. Ela inclui também a ajuda externa recebida para esse efeito (monetária e não-monetária)" (Registro Sul-Americano de Gastos Agregados em Defesa 2006-2015 2017, 61). Contam, de acordo com a definição adotada, os recursos gastos pelas Forças e suas agências, assim como demais setores com atuação na defesa externa do país. Não inclui, portanto, gastos atrelados à segurança interna, mesmo que empregando meios das Forças Armadas.

Essa metodologia contém algumas particularidades regionais. Em comparação com o SIPRI, por exemplo, a metodologia do CDS inclui como gastos militares a ajuda externa recebida, não a ajuda externa oferecida (Bromley and Solmirano 2012). Em relação à metodologia da Cepal, Saint-Pierre e Palacios Júnior (2014) destacam que, a partir de 2002, na V 
Conferência de Ministros de Defesa das Américas, no âmbito da OEA, os Estados da região ampliaram seu uso, pois estava sendo empregada com êxito entre Argentina e Chile. Os autores destacam que essa metodologia baseou-se em uma convergência da dimensão conceitual acerca das questões relativas à defesa, de modo a manter o seu escopo como segurança externa do Estado, para a seguir ocupar-se "de quantificar e compatibilizar os gastos” (Saint-Pierre and Palacios Júnior 2014, 28). Como mencionado anteriormente, a metodologia cepalina serviu como base para a metodologia posteriormente implementada na Unasul. Alguns desses avanços estão em linha, inclusive, com considerações que a própria Cepal tece ao avaliar o resultado da aplicação da metodologia para os casos de Argentina e Chile, aventando as condições necessárias para que outros países possam aplicar uma metodologia para comparação de gastos militares (Cepal 2005). Aspectos como a especificação detalhada dos gastos (em categorias), a incorporação de dados relativos a variáveis macroeconômicas como o PIB, o que permite que sejam apresentados gastos percentuais em defesa em relação ao $\mathrm{PIB}$, e dados relativos à variação entre o gasto em defesa e a variação do PIB foram adicionados no documento do CDS.

O Inventário Militar dos países da América do Sul também conta com uma metodologia que seleciona e padroniza o envio de informações a serem enviadas pelos Estados membros ao CDS, compiladas e arquivadas no CEED. Essa metodologia foi estabelecida dentre os objetivos do Plano de Ação de 2012 e, no mesmo ano, na Quarta Reunião Ordinária dos Ministros de Defesa, acordou-se acerca do modelo de transparência a ser implementado.

O Registro Sul-Americano de Inventários Militares (RESIM) é composto pelo Estatuto, pelo Manual e pelo Formulário de Inventários Militares (FOSIM), e é destacado em um desses documentos como uma "experiência renovada de transparência de inventários militares e um aprofundamento das medidas de Fomento à Confiança e à Segurança em nível regional” (Manual para Uso do Formulário Sul-Americano de Inventários Militares 2015, n.p). Como no caso dos gastos militares, o CDS alcançou uma conceituação comum para identificar o sistema que comporia as informações do inventário militar. Devem ser reportados, segundo o Manual para Uso do Formulário Sul-Americano de Inventários Militares (2015, n.p)

sistemas de armas, armamentos, meios e material das forças militares de cada país, incluindo o armamento individual, ficando excluídas as munições correspondentes aos mesmos. Em termos gerais, esta definição se aplica ao inventário do Exército, da Armada e da Força Aérea, para cumprir as funções de defesa que lhes encomenda o Estado. 
Apenas material de uso especificamente militar é considerado para fins do inventário e as informações devem incluir o período do serviço operativo do material, desde a sua entrada em operação até a saída do serviço operativo. Determinou-se também que os dados recebidos pelo CEED só poderão ser publicizados com autorização dos países, sob a regra do consenso, mantendo, até lá, confidencialidade e uso restrito ao CEED e CDS. Além da definição conceitual e dos critérios que definem essa metodologia, há direcionamentos para a apresentação e preenchimento das informações com o objetivo de padronizar o tipo de informação desejada pela instituição.

O Registro Sul-Americano de Inventários Militares, como o próprio Manual (2015, n.p) destaca, apresenta uma "relação direta com a metodologia para medir os gastos em defesa, especialmente no que diz respeito à informação de investimentos em recursos relativos a sistemas de armas, materiais e equipamentos, de acordo com o usuário final dos meios e as unidades executoras em matéria de gastos", dando mais transparência a esse conjunto de dados militares dispendidos pelos países sul-americanos.

O terceiro tema a ser debatido que se insere no conjunto de MCCs definidos pelo CDS e CEED consiste na defesa dos recursos naturais e cooperação em caso de desastres naturais. Apesar de ser um tema mencionado com recorrência nos documentos, de forma crescente e mais elaborada ao longo dos anos, e ser objeto de um estudo direcionado ao problema no CEED, as medidas de confiança nessa área ainda são majoritariamente propositivas.

As iniciativas relacionadas a essa área foram incorporadas no estudo "América do Sul 2025". O objetivo deste estudo é, a partir da perspectiva de segurança e da defesa regionais, a identificação dos possíveis fatores de risco ou ameaças nessa esfera. A primeira parte do documento, lançada em 2015, consiste em uma avaliação acerca da demanda e uso dos recursos estratégicos na atualidade e como tendência para 2025. Tal proposição assume que a América do Sul pode articular-se como um espaço geoestratégico próprio, usando seus recursos naturais estratégicos como base para garantir maior autonomia e segurança regional. No que diz respeito à metodologia, o estudo é um informe prescritivo dos recursos estratégicos existentes nos países, no qual deveria informar-se as ações concretamente alcançadas no setor de defesa para cumprir o objetivo de proteger os recursos naturais.

A segunda parte do documento foi incorporada em dezembro de 2018 e dedica-se a tratar dos recursos estratégicos em sua dimensão transfronteiriça, o que demandaria cooperação política para sua proteção. O estudo pretendeu identificar a relação entre defesa e recursos naturais e que fatores indicam vulnerabilidades e disfuncionalidades ${ }^{16}$ para a adequada prote- 
ção dos recursos. O segundo fator foi propor estratégias a fim de superar as vulnerabilidades identificadas (CEED 2018, 9).${ }^{17}$ Todavia, não foi possível chegar a uma proposta de metodologia, pois o caminho até aqui foi o mesmo com relação aos demais temas: construir conceitos comuns, por exemplo, nesse caso, de vulnerabilidade e disfuncionalidade, para desenvolver os passos seguintes.

O documento aponta o tema como de caráter subsidiário ou secundário para as forças armadas da região e que se desenvolve com cooperação interagências. Além disso, denota também medidas concretas para a superação efetiva dos problemas identificados, como ações de regulamentação operativa de disposições normativas, efetivação de mecanismos permanentes da área de defesa, assim como ações para otimizar a elaboração inter-agência/inter-jurisdicional e fortalecer as capacidades operativas uma vez que se identificou a insuficiência de equipamento necessário para os desastres naturais, estabelecer um "sistema" de monitoramento de área remotas e um atlas de capacidades regionais para "operacionalizar um mecanismo regional” de recursos que se coloquem disponíveis de um país para o outro em casos de desastres naturais e preservação do meio-ambiente (CEED 2018, 30).

Como parte de suas conclusões, o estudo registra que os cenários futuros apontam para um possível crescimento da necessidade de coordenação interagências nesse tema, o que incidiria no aumento das ações subsidiárias para as forças, uma vez que esse tema não é propriamente de defesa. A atenção aos recursos estratégicos e aos desastres naturais, assim como o interesse em desenvolver iniciativas cooperativas nesse tema, já se encontram presentes no conjunto das MCCs produzidas pela OEA e, como mencionado anteriormente, foi objeto de crescente interesse no âmbito do CDS e do CEED.

Finalmente, a proposta mais recente de metodologia refere-se à política de gênero na área da defesa. Tal proposta estruturou-se a partir de matrizes quantitativas e qualitativas para o diagnóstico da incorporação da mulher no setor de defesa e militar. Do ponto de vista quantitativo dimensionou-se a participação da mulher nas Forças Armadas, com uma matriz que considera as Forças (Exército, Marinha, Aeronáutica e Outras Instâncias do Setor Defesa) com dados como ano de ingresso do pessoal feminino nas Forças Armadas; números necessários para alcançar a proporcionalidade em dimensões frente ao contingente total e, deste total, o número que representa o contingente feminino nas Forças, assim como de oficiais graduados nas Escolas de Comando e de oficiais femininos exercendo comando. Do ponto de vista qualitativo, reuniram-se elementos para dimensionar questões mais subjetivas, por vezes difíceis de quantificar, 
mas fundamentais para entender os desafios enfrentados pelas mulheres, como fatores contribuintes para a permanência ou saída das mulheres nas forças, impacto de sua carreira em sua família e filhos, e aspectos da cultura institucional.

O CDS apostou na construção de metodologias como forma de padronizar a troca de informações, facilitando a sistematização e comparação dos dados entre os países-membros. Assim como as metodologias associadas aos gastos em defesa e sobre o Inventário Militar, que produziram documentos derivados das informações fornecidas pelos Estados membros, ainda que difundidas com seus dados agregados, a metodologia sobre a política de gênero na defesa produziu um relatório analítico e descritivo ${ }^{18}$ de informações sobre o assunto. Esse relatório foi publicado em sua primeira parte em abril de 2019 apresentando a consolidação das informações coletadas a partir da metodologia criada para mapear e informar o envolvimento da mulher no setor de Defesa.

Além das quatro temáticas em que se buscou construir metodologias comuns para sistematização e padronização da coleta e produção de informações - gastos em defesa, inventário militar, recursos estratégicos e assistência a desastres naturais, e política de gênero — outras três iniciativas associadas ao fortalecimento da confiança também são contempladas pelos documentos da organização: a indústria de defesa, a segurança e defesa cibernética, e os exercícios militares conjuntos. Iniciativas nessas três áreas são bastante distintas em seu estágio de desenvolvimento e alcance, sendo as duas primeiras ainda de caráter propositivo no que concerne a coordenação e cooperação multilateral, embora ocupem espaço de destaque nas preocupações do bloco; a última, o incentivo à manutenção de uma atividade prevista como MCC desde as primeiras discussões sobre o tema no plano hemisférico, e que desempenha, ainda que com alcance limitado, um mecanismo de socialização institucional, cultural e doutrinária entre as Forças Armadas.

\section{CONSIDERAÇÕES FINAIS}

A análise dos documentos do CDS entre 2009 e 2016 sugere interesse por parte dos Estados membros em adotar MCCs como medida de transparência regional, interesse esse já demonstrado em outros fóruns multilaterais desde a década de 90 . O acúmulo e a repetição do desenvolvimento de metodologias para o compartilhamento de informações sugerem que os Estados reconheceram a validade da padronização na coleta e divulgação de suas informações como um instrumento adequado para fortalecer a confiança entre os países e buscar consensos regionais. Convém fazer a 
ressalva de que a falta de publicização de dados individualizados dos países torna difícil alcançar quaisquer conclusões sobre a efetiva implementação, ou avanço nas práticas, de padronização. Nesse sentido, informações que permitissem a comparação da periodicidade de envio por parte dos países e o grau de adequação no preenchimento dos formulários contribuiriam para compreender melhor qual grau de representatividade a Unasul alcançou enquanto agente impulsionador de práticas de fortalecimento da confiança na área de defesa para a América do Sul.

Além disso, uma dimensão relevante das MCCs, as atividades relacionadas à verificação das informações disponibilizadas ao órgão pelos países não tiveram nenhum avanço significativo. Houve intenção de se criar mecanismos de verificação sobre os dados referentes aos gastos em defesa, mas não há evidências de que o CDS ou CEED tenham sido acionados para tal fim.

A avaliação das iniciativas dedicadas ao fortalecimento da confiança, no entanto, demonstra que o organismo parece ter sido mais bem-sucedido em apresentar tendências no contexto sul-americano do que propriamente fortalecer a confiança por meio da disseminação de informações. As restrições impostas à publicização de dados individualizados dos países aparecem como um empecilho significativo ao processo de transparência, embora seja razoável assumir que essas informações fossem acessíveis para os países membros. Dessa forma, atuaria como um instrumento de troca de informação e aumento da confiança entre eles.

Por outro lado, a própria criação do CEED funcionou como um ganho institucional relevante para MCCs na região. Não somente se trata de um organismo que compilava informações como também funcionou como consultor para o preenchimento de formulários sobre gastos de defesa e sobre o inventário militar. Nesse sentido, agregar os gastos em defesa como os países sul-americanos o fizeram mostra o grau de coesão que foi possível alcançar e como se obteve um resultado que é muito almejado, mas pouco obtido, por outras regiões (Magalhães, Silva, and Feliciano 2017). Assim, embora não se encontre atualmente garantias de como se dará a continuidade desse processo, podendo inclusive ser produzido "sob a orientação de outras forças políticas, mesmo com reformulações ou redefinições” (Bragatti and Gonçalves 2018, 91), o acumulado em cooperação em defesa obtido nos últimos anos resultou da convergência de pensamento que vigorou e estruturou as políticas de distensionamento e cooperação nesse período.

O relatório elaborado pelo Grupo de Especialistas Governamentais em Registro de Armas Convencionais da ONU (UN Group of Governamental Experts on the Register of Conventional Arms) aponta que um dos motivos pelos quais os países deixam de enviar as informações demandadas é a 
“inadequada capacidade institucional”, além de preocupações de natureza política e de segurança, justamente o que as medidas de confiança buscam mitigar (Bromley and Solmirano 2012, 25). De fato, o baixo grau de profissionalismo e treinamento das burocracias de defesa dos países da América do Sul, cujo quadro ainda se encontra bastante militarizado (Diamint 2017, 251), sugere que limitações técnicas sejam um elemento a interferir na atuação dos Estados em cumprir com as obrigações de transparência. $\mathrm{O}$ CEED contribuía em atender uma importante lacuna nesse sentido.

Convém observar que, apesar do espaço político reduzido atualmente na América do Sul para seguir com mecanismos regionais, identificar se, em que medida e de que forma o setor de defesa dos países da região incorporou institucionalmente as metodologias propostas pelo bloco, permitirá avaliar com mais clareza o impacto que as dinâmicas associadas às MCCs na Unasul tiveram sobre a transparência da defesa na região. Com isso, por um lado, poderia-se oferecer uma indicação sobre o impacto que as medidas de padronização propostas pelo CDS e CEED tiveram sobre como os países da região reportam seus gastos em defesa; e, por outro, como essas práticas continuarão a ser desenvolvidas nos próximos anos, seja em nível bilateral, regional ou hemisférico.

\section{REFERÊNCIAS}

Bragatti, Milton C., and Rubén M. Gonçalves. 2018. "Cooperação na área de defesa na Unasul: um balanço do conselho de defesa sul-americano (CDS) e seus limites atuais". Revista de Relaciones Internacionales, Estrategia y Seguridad 13, no. 2 (May): 73-95.

Bromley, Mark, and Catalina Perdomo. 2005. "CBM en América Latina y el efecto de la adquisición de armas por parte de Venezuela (DT). Real Instituto Elcano de Estudios Internacionales y Estratégicos, Documento de Trabajo, n. 41, oct.

.2012. "Transparency in Military Spending and Arms Acquisitions in Latin America and the Caribbean". SIPRI Policy Paper no. 31 (Jan.). SIPRI — Stockholm International Peace Research Institute.

Caro, Issac. 1995. "Medidas de Cofianza mutual en Sudamerica". Estudios Internacionales 28 no. 109: 37-57.

CDS - Conselho Defesa Sul-Americano. 2008. "Estatuto del Consejo de Defensa Suramericano." http://ceed.unasursg.org/Espanol/o9-Downloads/Normativa/ Estatuto-CDS.pdf. 
n.d. "Manual para Uso del Formulario Sudamericano de Inventarios Militares (FOSIM)". http://ceed.unasursg.org/Espanol/o9-Downloads/DocLineas/RESIM-Matriz.pdf.

"Planes de Acción. 2009-2016". http://ceed.unasursg.org/Espanol/o8CDS/08.2-Plan-Accion.html.

CEED - Centro de Estudos Estratégicos de Defesa. n.d. "Apresentação". http:// ceed.unasursg.org/Portugues/o1-CEED-port/o1-CEED-port.html.

n.d. "Estudo Prospectivo Sul-America 2025." http://ceed.unasursg.org/ Espanol/09-Downloads/Biblioteca/ RRNN2025.pdf.

n.d. "Estudo Prospectivo Sul-America 2025. Segunda Parte." http://ceed. unasursg.org/Espanol/O9-Downloads/Biblioteca/RRNN-2P-LIBRO-COMPESP.pdf.

n.d. "Estatuto Registro Sul-Americano de Inventários Militares." http://ceed.unasursg.org/Portugues/o9-Downloads/Docs-Lineas-Port/RESIM_ ESTATUTO-PORT.pdf.

n.d. "Guía Metodológica da la Matriz Optimizada Área de Investigación: Política de Defensa. Estudio sobre Política de Género: La Mujer en el ámbito de la defesa". http://ceed.unasursg.org/Espanol/09-Downloads/Doc-Lineas/ GENERO_GUIA.pdf.

. n.d. "Informe Final: Desenho de uma Metodologia Comum de Medição de Gastos de Defesa”. http://ceed.unasursg.org/Espanol/o9-Downloads/DocLineas/Metodologia_Comun. pdf.

. "Informe sobre os Termos de Referência para os Conceitos de Segurança e Defesa na América do Sul”. http://ceed.unasursg.org/Espanol/o9-Downloads/ Biblioteca/INFORME_CONCEPTOS_SEG_DEF.pdf.

n.d. "La Defensa y los Recursos Naturales - Contribuciones para una Estrategia Regional”. http://ceed.unasursg.org/Espanol/o9-Downloads/ Biblioteca/RRNN2025.pdf.

. 2012-2016. "Planes de Trabajo. 2012-2016". http://ceed.unasursg.org/ Espanol/01-CEED/01.3-Planes.html.

. n.d. "Registro Sudamericano de Gastos Agregados en Defensa 20062015. Edición Especial”. http://ceed.unasursg.org/Espanol/o9-Downloads/ Biblioteca/RSGAD-2006-2015-WEB.pdf . 
2019. "La Mujer en el ámbito de la Defensa en Suramérica”. http://ceed. unasursg.org/Espanol/09-Downloads/Biblioteca/GEN-2019.pdf.

CEED - Centro de Estudios Estratégicos de Defensa. 2018 "Estudio Prospectivo Suramérica 2025. Segunda Parte.” Buenos Aires (diciembre).

CEPAL. Comissão Econômica para América Latina e Caribe. Centro Regional para la Paz, el Desarme y el Desarrollo en América Latina y el Caribe. 2001. "Avances em la confianza mutua y transparência del gasto em defensa entre Chile y Argentina". Comunicados de Prensa. 29 de novembro. https://www.cepal. org/cgi-bin/getProd.asp?xml=/prensa/noticias/comunicados/9/8699/P8699. $\mathrm{xml} \& \mathrm{xsl}=/ \mathrm{prensa} / \mathrm{tpl} / \mathrm{p} 6 \mathrm{f} . \mathrm{xsl} \&$ base $=/ \mathrm{prensa} / \mathrm{tpl} /$ top-bottom.xsl Accessed Dec. 24, 2020.

2005. "Documento de proyecto. Metodología para la comparación de los gastos militares." Santiago, Chile (Oct.).

Cheung, Tai Ming, and Jordan Wilson. 2014. "IGCC White Paper on Defense Transparency in Northeast Asia. 2013-2014 Edition”. U.S. San Diego Policy Briefs, U.C. Institute on Global Conflict and Cooperation, Northeast Asia Defense Transparency Project. https://escholarship.org/uc/item/oqq7x94p-.

Conference on Security and Co-Operation in Europe. n.d. "Final Act. Helsinki 1975.” https://www.osce.org/helsinki-final-act.

Desenho de uma Metodologia Comum de Medição de Gastos de Defesa 2011

Desjardins, Marie-France. 2014 (2004). Rethinking Confidence-Building Measures. Obstacles to agreement and the risks of overselling the process. New York: Routledge. E-Book. ISBN 13.978-0-198-29321-7 (pbk).

Diamint, Rut. 2017. "Defense Management in South America: bureaucracy and diplomacy". In Power Dynamics and Regional Security in Latin America, edited by Marcial Suarez, Rafael Villa, andBrigitte Weiffen: 247-270. Londres: Palgrave Macmillan.

Donadio, Marcela. 2010. "El Consejo Sudamericano de Defensa y el papel en el desarrollo de la confianza mútua”. CEED. Confianza y Seguridad en America del Sur. Quito: Publicación del Consejo de Defensa Suramericano.

CDS - CONSELHO DEFESA SUL-AMERICANO. 2008. "Estatuto del Consejo de Defensa Suramericano." http://ceed.unasursg.org/Espanol/o9-Downloads/ Normativa/Estatuto-CDS.pdf. Acessed Dec 19, 2018. 
Flemes, Daniel, and Michael Radseck. 2009. "Creating Multilevel Security Governance in South America”. Giga Working Paper 117.

Lindsay, Jon. 2011. "Defense transparency: seeking a definition for a paradoxical concept." DTP Policy Briefs - Policy Brief 5. https://escholarship.org/uc/ item/3485013j.

Magalhães, Diego Trindade, Rafael Lemos Silva, and Júlia de Mello Feliciano. 2017. "Construção de confiança e transparência militar na UNASUL: avanços e desafios". Revista Conjuntura Austral 8, no. 42 (Jun./Jul.): 61-77.

Manual para Uso do Formulário Sul-Americano de Inventários Militares 2015

Mares, David. 2001.Violent Peace: militarized interstate bargaining in Latin America. New York: Columbia University Press.

. 2012. "Por que os latino-americanos continuam a se ameaçarem - o uso da força militar nas relações intra latino-americanas." Varia Historia 28, no. 48 (Jul./Dez.): 599-625.

OEA - Organização dos Estados Americanos. 2003. "Consenso de Miami. Declaração dos peritos sobre medidas de fortalecimento da confiança e da segurança: recomendações à conferência especial sobre segurança disposta pela cúpula”. OEA/Ser.K/XXIX. RESEGRE/doc.4/o3 rev. 2.

2010. "Ata de Encerramento. Declaração de Santa Cruz de La Sierra. IX Conferência de Ministros da Defesa das Américas". 22-25 Novembro. http://scm. oas.org/pdfs/2010/CP25453P.pdf.

. 2017. "Chairman's Conclusions. The Seventh Meeting of the Forum on Confidence-and-Security-Building Measures”. OEA/Ser.K/XXIX CSH/FORO$\mathrm{VII} /$ doc.5/17.

2018. "Lista Consolidada de Medidas de Fortalecimento da Confiança e Segurança (MFCSs)". Conselho Permanente da Organização dos Estados Americanos, Comissão de Segurança Hemisférica. 5 Junho. OEA/Ser.G CP/CSH$1870 / 18$.

OSCE - Organización para la Seguridad y la Cooperación en Europa. 2011. Documento de Viena 2011 sobre Medidas Destinadas a Fomentar la Confianza y la Seguridad. 30 Noviembre.

ONU - General Assembly. n.d. "General and complete disarmament”. http:// www.un.org/documents/ga/res/46/a46ro36.htm. 
Rojas Aravena, Francisco. 2000. "América Latina, las medidas de confianza mutua y de seguridade regional. Evaluación y perspectivas". Estudios Internacionales 33, no. 129 (Ene- Mar): 18-32.

2002. "Las Medidas de Confianza Mutua y de Seguridad: perspectivas desde Chile". Fuerzas Armadas y Sociedad 17, no. 1-2 (Ene-Jun): 32-43.

Registro Sul-Americano de Gastos Agregados em Defesa 2006-2010 2014

Registro Sul-Americano de Gastos Agregados em Defesa 2006-2015 2017

Relatório sobre os Termos de Referência para os Conceitos de Segurança e Defesa na América do Sul 2011, n.p

Rojas Aravena, Francisco (Org.). 1996. Balance estratégico y medidas de confianza mutua. Santiago, Chile: FLACSO-Chile.

Rojas Aravena, Francisco. 2000. América Latina, las medidas de confianza mutua y de seguridade regional. Evaluación y perspectivas. Estudios Internacionales 33, no. 129 (ene- mar): 18-32.

Rojas Aravena, Francisco. 2002. Las Medidas de Confianza Mutua y de Seguridad: perspectivas desde Chile. Fuerzas Armadas y Sociedad 17, no. 1-2 (ene-jun): 32-43.

Saint-Pierre, Héctor, and Alberto M. Palacios Júnior. 2014. "As medidas de confiança no Conselho de Defesa Sul-americano (CDS): análise dos gastos em Defesa (2009-2012)." Revista Brasileira de Política Internacional 57, no. 1: 22-39.

Ugarte, José Medeiros. 2016. "Argentina, Brasil y Chile: análisis comparativos de sus políticas de defensa, de su evolución previsible, y de sus perspectivas de cooperación.” In Inserção Internacional da Argentina e do Brasil: desafios da política externa $e$ de defesa, edited by André Reis da Silva, and Eduardo Munhoz Svartman. Porto Alegre: Ed UFRGS.

Varas, Augusto, and Isaac Caro (Eds.). 1994. Medidas de confianza mutua en América Latina. Chile: FLACSO. 


\section{NOTAS}

1. A confiança, como parte do fortalecimento da segurança, visa à transparência, ao entendimento mútuo e à segurança regional, e seu principal desafio consiste em evitar o uso da força entre os atores.

2. Mares (2001; 2012) elenca as disputas militarizadas na região e as qualifica a partir de seu nível de hostilidade, considerando-as de baixa intensidade.

3. Mesmo que se questione se essa condição sustentada por Mares se aplica a toda a América do Sul nos anos aqui em análise, esforços relacionados à transparência em defesa na região ainda carecem de complementação em todas as sub-regiões do continente.

4. Complementam esses documentos os Tratados sobre o Controle de Armas Convencionais na Europa (Treaties on Conventional Arms Control in Europe) (CFE) e o Tratado Open Skies, parte do Quadro para o Controle de Armas (Framework for Arms Control), elaborado na Cúpula de Lisboa (Lisbon Summit) em 1996 (OSCE 2011).

5. Armoured Combat Vehicles, especificados no anexo III do documento.

6. Cabe mencionar que um conjunto de tratados internacionais sobre temas específicos da área de segurança e defesa, que também se caracterizam como MCCs, foram assinados pelos países da região. Em especial, ressalta-se o Tratado para a Proscrição de Armas Nucleares na América Latina e no Caribe, conhecido como o Tratado de Tlateloco.

7. Para consultar sobre as três conferências mais importantes nessa área no hemisfério, ver https://www.oas.org/csh/portuguese/fdacsnew.asp.

8. O que, de acordo com Desjardins, ocorre em diversas outras iniciativas de construção da confiança ao redor do mundo (2014).

9. A Declaração de Santa Cruz de La Sierra, resultado da IX Conferência de Ministros da Defesa das Américas, em novembro de 2010, por sua vez, afirma: “[reconhecer o ] esforço realizado durante o ano de 2010 pelo CDS, para gerar uma metodologia sul-americana de medição e informação dos gastos de defesa; e promovem a mesma como base para o desenvolvimento de uma metodologia hemisférica comum". (OEA 2010, 9)

10. Esses documentos são as Atas das Reuniões da Instância Executiva do CDS e as das Reuniões de Grupos de Trabalhos do CDS que se encontram disponíveis. Convém destacar que os Planos de Ação e de Trabalho são documentos de ação mais consolidados do que as Atas, de modo que as contribuições destas apenas pontualmente foram incorporadas neste trabalho.

11. Os Planos de Ação foram elaborados nos anos de i) 2009-2010; ii) 2010-2011; iii) 2012; iv) 2013; v) 2014; vi) 2015 e vii) 2016. 
12. Os Planos de Trabalho, sete em sua totalidade e em número de cinco consultados nessa pesquisa, foram elaborados anualmente desde 2012.

13. Os Planos de Ação do CDS foram divididos em quatro eixos temáticos: Políticas de Defesa; Cooperação Militar, Ações Humanitárias e Operações de Paz; Indústria e Tecnologia de Defesa; Formação e Capacitação. Os Planos de Trabalho do CEED são estruturados com base em três áreas de pesquisa: Política de Defesa, Riscos e Ameaças para a Segurança Regional; Institucionalidade dos Sistemas Nacionais de Defesa; Prospectiva e Estratégia.

14. Declaração de Santiago sobre Medidas de Fortalecimento da Confiança e Segurança, OEA/Ser.K/XXIX.2, COSEGRE/doc.18/95 rev.2, 10 novembro 1995.

15. A metodologia proposta pode ser encontrada em https://www.cepal. org/es/publicaciones/6459-metodologia-estandarizada-comun-lamedicion-gastos-defensa. O Consenso de Miami da OEA, de 2003, reconhecem avanços também na aplicação dessa metodologia entre Chile e Peru (OEA 2003, 4).

16. Os conceitos podem ser entendidos como marcos analíticos importantes na identificação de fatores e situações que podem resultar, desde a perspectiva da defesa, em vulnerabilidades e disfuncionalidades na proteção dos recursos naturais da região e nas propostas que podem ser elaboradas para superá-las. Assim sendo, a vulnerabilidade é entendida como as "condições objetivas e próprias de um ator - o Estado neste caso - que podem originar, facilitar e/ou promover a aparição ou materialização de situações ou fenômenos prejudiciais ou, inclusive, facilitar ou promover a emergência de ações negativas para esse ator - Estado - proveniente de terceiros" (CEED 2018, 15). Já a disfuncionalidade se caracteriza pelas condutas desse mesmo Estado que não são eficazes na proteção de seus interesses.

17. Estudo Prospectivo América do Sul 20252018.

18. O informe destaca a sua natureza dupla, ou seja, é descritivo - "da atual realidade regional em matéria de gênero no âmbito da defesa”, e é analítico-explicativo no que se refere à apreciação sobre "os fatores que incidem (possibilitando ou obstaculizando) a institucionalização das práticas e políticas gênero" no tocante às Forças Armadas da região (tradução nossa) (CEED 2019, 9). 


\section{TRANSPARÊNCIA EM DEFESA: UM PANORAMA DAS MEDIDAS DE CONSTRUÇÃO DE CONFIANÇA NA UNASUL (2009-2016)}

\section{RESUMO}

Este trabalho tem como objetivo apresentar um panorama do desenvolvimento das medidas de construção e fortalecimento da confiança (MCCs) na Unasul entre 2009 e 2016, a partir da leitura dos documentos produzidos pelo Conselho de Defesa Sul-Americano e pelo Centro de Estudos Estratégicos de Defesa deste organismo. Discute-se quatro áreas compreendidas como MCCs de acordo com o grau de relevância identificado nos documentos. Dois pontos se destacam neste conjunto de iniciativas: a criação de metodologias para a padronização da coleta de informações e a construção de consensos acerca de conceitos na área de defesa.

Palavras-chave: América do Sul; Transparência em Defesa; Medidas de Fortalecimento de Confiança.

\section{ABSTRACT}

This paper aims to present an overview of the development of confidence-building measures (MCCs) in Unasur between 2009 and 2016 from the interpretation of documents produced by the South American Defense Council and the Center for Strategic Defense Studies. Four areas understood as MCCs are discussed according to the degree of relevance identified in the documents. Two points stand out in this set of initiatives: the creation of methodologies to standardize the collection of information and the building of regional consensus around concepts in defense.

Keywords: South America; Transparency in Defense; Confidence-Building Measures. 